\title{
Factors Associated with Poor Antiepileptic Drugs Adherence in Below Poverty Line Persons with Epilepsy: A Cross-Sectional Study
} \author{
Parmal Singh ${ }^{5}$ \\ 1Department of General Medicine, Kalpana Chawla Government \\ Medical College (KCGMC), Karnal, Haryana, India \\ ${ }^{2}$ Department of Psychiatry, Kalpana Chawla Government Medical \\ College (KCGMC), Karnal, Haryana, India \\ ${ }^{3}$ Department of Paediatrics, PGIMER Satellite Centre Sangrur, \\ Punjab, India \\ ${ }^{4}$ Department of Community Medicine, Gian Sagar Medical College, \\ Banur, Patiala, Punjab, India \\ ${ }^{5}$ Department of Community Medicine, Adesh Medical College, \\ Ambla, Haryana, India
}

Nikhil Govil ${ }^{1}$ Savita Chahal ${ }^{2} \quad$ Nishu Gupta ${ }^{3} \quad$ Amandeep Singh Kaloti ${ }^{1} \quad$ Anuradha Nadda ${ }^{4, \odot}$

J Neurosci Rural Pract:2021;12:95-101

\author{
Address for correspondence Savita Chahal, Department of \\ Psychiatry, Kalpana Chawla Government Medical College (KCGMC), \\ Karnal, Haryana, 132001, India (e-mail: savi1310@gmail.com).
}

\begin{abstract}
Keywords

- epilepsy

- anti-epileptic drugs

- non-adherence

- below poverty line

Background Adherence to antiepileptic drugs (AED) is essential for adequate seizure control in epilepsy. People with low socioeconomic status are more vulnerable to poor adherence to AED. The present study aimed to explore factors associated with poor adherence to antiepileptic drugs in below poverty line (BPL) persons with epilepsy (PWE).

Methods The research had a cross-sectional design with inclusion of persons aged 18 to 65 years and an established diagnosis of epilepsy. Holding a BPL card (Yellow card) was taken as a measure for BPL criteria. Adherence to antiepileptic drugs was assessed using medication adherence rating scale (MARS). Univariate analysis with Chi-square test was used to determine the association between various variables and AED adherence, while the predictors of adherence were identified using multivariate logistic regression analysis.

Results There was a total of 88 BPL PWE. The mean age of male and female patients was $35.0 \pm 15.0 \& 32.0 \pm 10.1$ years, respectively. Adherence for drugs were found to be $30.7 \%$ and nonadherence to be $44.3 \%$. Low (illiterate or primary) education (OR $0.041[0.01-0.21])$, polytherapy (OR 0.088 [0.02-0.40]), and substance abuse (OR 0.05 [0.01-0.58]) were found to have significant association with nonadherence to AEDs. Age, gender, marital status, family composition, occupation, rural urban background, distance from health care facility, duration of epilepsy, and side effects of AED were not found to have significant association with adherence.

Conclusion There is a need for psychoeducational programs for the people having low education status and polytherapy to form positive beliefs in AEDs. Substance abuse should also be addressed while treating them.
\end{abstract}

DOI https://doi.org/ $10.1055 / \mathrm{s}-0040-1721200$ ISSN 0976-3147. (c) 2021. Association for Helping Neurosurgical Sick People.

This is an open access article published by Thieme under the terms of the Creative Commons Attribution-NonDerivative-NonCommercial-License, permitting copying and reproduction so long as the original work is given appropriate credit. Contents may not be used for commercial purposes, or adapted, remixed, transformed or built upon. (https://creativecommons.org/licenses/by-nc-nd/4.0/) Thieme Medical and Scientific Publishers Pvt. Ltd., A-12, 2nd Floor, Sector 2, Noida-201301 UP, India 


\section{Introduction}

Epilepsy is a condition characterized by recurrent (two or more) epileptic seizures, unprovoked by any immediate identifiable cause. ${ }^{1}$ As per the World Health Organization (WHO), there are approximately 50 million persons with epilepsy (PWE) globally, out of which $80 \%$ belong to developing countries. The prevalence of epilepsy in India is 5 to 10 per 1000 population. ${ }^{2}$

Antiepileptic drug (AED) therapy has been demonstrated to be effective in $70 \%$ of the patients in achieving seizure control. ${ }^{3}$ However, adherence to treatment remains a primary determinant in effective seizure control. Rate of adherence can be described as the percentage of the prescribed doses of the medication actually taken by the patient over a specified time period. ${ }^{4}$ The magnitude of nonadherence varies widely, which is attributable to the methodology used in the study and heterogeneity of the populations being studied. The extent of AED nonadherence among PWE has been found to vary between $27 \%$ to $43 \%$ in previous Indian studies. It has been observed in previous research works that people who belong to economically deprived category are more likely to discontinue epilepsy treatment., ${ }^{5,6}$ Although the prevalence of nonadherence and role of various factors influencing the adherence to AEDs has been studied in previous research works, there is, however, dearth of published literature regarding the same among PWE who are below poverty line (BPL). So, the present study aimed to explore various factors associated with nonadherence to AEDs in BPL PWE.

\section{Methodology}

\section{Study Design}

Ethical approval for the study was sought from the institutional ethics committee (KCGMCH/IEC/2019/52 dated 15.07.2019). It was a cross-sectional study performed in the outpatient department of Kalpana Chawla Government Medical College (KCGMC), Karnal, from July 2019 to March 2020. The study subjects with an established diagnosis of epilepsy were recruited from both general medicine and psychiatry outpatient clinic after screening as per the inclusion and exclusion criteria. The diagnosis of epilepsy in the subjects was primarily based on detailed clinical history and a thorough neurological assessment by a qualified physician or neuropsychiatrist. Electroencephalography (EEG) and neuroradioimaging techniques (i.e., CT and MRI) were considered as supportive evidence for the diagnosis but not mandatory. Adult patients of either gender aged 18 to 65 years with an established diagnosis of epilepsy who had been on AEDs for at least 6 months and were BPL card (Yellow card) holders and provided written informed consent were included in the study. Exclusion criteria were patients of epilepsy i) who were either pregnant or breastfeeding, ii) with comorbid mental retardation and serious mental illnesses, iii) who had serious neurological deficit, iv) warranting hospitalization due to any comorbid serious physical illness.

\section{Study Tools}

1. Proforma for sociodemographic, epilepsy, and AEDrelated variables: A special proforma specifically designed for the study was used to gather sociodemographic, epilepsy, and AED-related variables.

2. Medication adherence rating scale (MARS): AED adherence was measured using MARS by Thompson et $\mathrm{al}^{7}$ The MARS consists of 10 items that require yes/no response. If any participant could not read, assisted application was used, where the investigator read out the questions and marked the appropriate response provided by the subject. The questionnaire assessed their behavior or attitude toward their medication during the past week. The scores $0-3,4-6$, and 7-10 were categorized as nonadherent, partial adherent, and adherent, respectively.

3. Questionnaire for assessment of reasons of AED nonadherence: A self-designed, semistructured questionnaire was used to assess various reasons of nonadherence to AED.

\section{Methods}

Taking 72\% prevalence ( $p$ ) of adherence to antiepileptic medication (Gurumurthy et al; in which socioeconomic status was significantly associated with adherence $)^{6}$ at $95 \%$ confidence interval, power of study $90 \%$, and considering $15 \%$ relative error (1). Using the $\mathrm{N}=\mathrm{Z}^{2}{ }_{\mathrm{X}} \mathrm{P}(1-\mathrm{P}) / \mathrm{I}^{2}$ formula, the sample size was estimated to be 67 . Taking $10 \%$ nonresponse rate, total sample size came out to be 74 .

Eighty-eight consecutive patients of epilepsy who met the eligibility criteria after screening as per inclusion and exclusion criteria were recruited in the study. Detailed information pertaining to sociodemographic variables (gender, age, education, occupation, marital status, rural-urban background, type of family, distance of residence from health care facility, substance use, medical comorbidities), epilepsy, and treatment-related variables (duration and type of epilepsy, type of therapy, availability of antiepileptic medication and side effects) were taken from all the study subjects. They were subsequently assessed for the AED adherence using MARS. Those found to have partial or nonadherence to medication were also enquired about reasons for the same, using a self-designed, semistructured questionnaire.

\section{Statistical Analysis}

Data were analyzed using SPSS version 20 (IBM Corp., Armonk, NY, USA). Descriptive statistics were applied for nominal variables. Chi-square test and univariate analysis was used to find the association of various factors with adherence. Predictors of nonadherence were determined using multivariate logistic regression (significance level set at $p \leq 0.05$ ).

\section{Results}

A total of 88 PWE with mean age $33.8 \pm 13.2$ years participated in this study. Mean age of male and female subjects was $35.0 \pm 15.0$ and $32.0 \pm 10.1$ years, respectively. Majority (76.1\%) of the subjects were in the age range of 18 to 45 years. Approximately half of the subjects were illiterate or educated till primary. One third of the people with epilepsy were 
employed. Among substance users, tobacco (79.2\%) was the most common substance used, followed by alcohol (37.5) and cannabis $(12.5 \%)$ (-Table $\mathbf{1})$.

Females had a relatively younger onset of epilepsy (mean age: $18.32 \pm 8.5)$ compared with males $(20.92 \pm 13.9)$.

Table 1 Sociodemographic characteristics of PWE $(n=88)$

\begin{tabular}{|c|c|}
\hline Variables & Number (\%) \\
\hline \multicolumn{2}{|l|}{ Gender } \\
\hline Male & $51(58.0)$ \\
\hline Female & $37(42.0)$ \\
\hline \multicolumn{2}{|l|}{ Age groups (in years) } \\
\hline $18-25$ & $34(38.6)$ \\
\hline $26-45$ & $33(37.5)$ \\
\hline$>45$ & $21(23.9)$ \\
\hline \multicolumn{2}{|l|}{ Education } \\
\hline Illiterate & $20(22.7)$ \\
\hline Primary & $27(30.7)$ \\
\hline Matriculation & $32(36.4)$ \\
\hline Graduation and above & $09(10.2)$ \\
\hline \multicolumn{2}{|l|}{ Occupation } \\
\hline Unemployed & $11(12.5)$ \\
\hline Student & $17(19.3)$ \\
\hline Homemaker & $30(34.1)$ \\
\hline Farmer & $08(9.1)$ \\
\hline Unskilled worker & $13(14.8)$ \\
\hline Skilled worker & $09(10.2)$ \\
\hline \multicolumn{2}{|l|}{ Marital Status } \\
\hline Married & $50(56.8)$ \\
\hline Single & $38(43.2)$ \\
\hline \multicolumn{2}{|l|}{ Background } \\
\hline Rural & $62(70.5)$ \\
\hline Urban & $26(29.5)$ \\
\hline \multicolumn{2}{|l|}{ Family composition } \\
\hline Nuclear & $44(50.0)$ \\
\hline Joint & $44(50.0)$ \\
\hline \multicolumn{2}{|l|}{$\begin{array}{l}\text { Distance of residence from health } \\
\text { care facility }(\mathrm{km})\end{array}$} \\
\hline $1-10$ & $31(35.2)$ \\
\hline $11-25$ & $33(37.5)$ \\
\hline $26-50$ & $20(22.7)$ \\
\hline$\geq 51$ & $04(4.5)$ \\
\hline \multicolumn{2}{|l|}{ Substance use } \\
\hline No & $64(72.7)$ \\
\hline Yes & $24(27.3)$ \\
\hline \multicolumn{2}{|l|}{ Physical comorbidities } \\
\hline No & $67(76.1)$ \\
\hline Yes & $21(23.9)$ \\
\hline
\end{tabular}

Abbreviation: PWE, persons with epilepsy.
Majority of the patients had generalized tonic clonic seizures (72.7\%) followed by focal (21.6\%). Almost half of the patients had epilepsy for more than 10 years. Polytherapy was used in $62 \%$ of patients, with sodium valproate $(71.6 \%)$ being the most common drug prescribed for treatment, followed by phenytoin (48.9\%). Almost one third of the patients had reported side effects from AEDs. Weight gain (7.9\%) was the most common side effect experienced by patients, followed by tremors (5.6\%) and sedation (4.5\%) (-Table 2 ).

Adherence to antiepileptic medication was found in 27 (30.7\%) patients. Partial adherence and nonadherence were noted in $22(25 \%)$ and 39 (44.3\%) subjects. Gender, age, occupation, marital status, background, family composition, distance of residence from health care facility, associated physical comorbidities, duration of treatment, side effects by AED, and cost of treatment were found to be nonsignificant on univariate analysis. However, low education, polytherapy, and substance use were found to have significant association with nonadherence to AED ( - Table 3). On applying multivariate logistic regression, low education (illiterate or educated

Table 2 Clinical characteristics of PWE $(n=88)$

\begin{tabular}{|c|c|}
\hline Variables & No. (\%) \\
\hline \multicolumn{2}{|l|}{ Duration of epilepsy (in years) } \\
\hline$<5$ & $18(20.5)$ \\
\hline $5-10$ & $23(26.1)$ \\
\hline$>10$ & $47(53.4)$ \\
\hline \multicolumn{2}{|l|}{ Duration of treatment (in years) } \\
\hline$<1$ & $16(18.2)$ \\
\hline 1 to 5 & $62(70.5)$ \\
\hline$>5$ & $10(11.4)$ \\
\hline \multicolumn{2}{|l|}{ Type of therapy } \\
\hline Monotherapy & $33(37.5)$ \\
\hline Polytherapy & $55(62.5)$ \\
\hline \multicolumn{2}{|l|}{ Seizure frequency/year } \\
\hline$<5$ episodes/ year & $28(31.8)$ \\
\hline 5-10 episodes/ year & $37(42.0)$ \\
\hline > 10 episodes/ year & $35(39.8)$ \\
\hline \multicolumn{2}{|l|}{ Frequency of AED therapy } \\
\hline Once daily & $14(15.9)$ \\
\hline Twice daily & $60(68.2)$ \\
\hline Thrice daily & $14(15.9)$ \\
\hline \multicolumn{2}{|l|}{ Noticeable side effects attributable to AED } \\
\hline Yes & $31(35.2)$ \\
\hline No & $57(64.8)$ \\
\hline \multicolumn{2}{|l|}{ Expenditure on AED therapy } \\
\hline Free & $64(72.7)$ \\
\hline Combined (free + purchased) ${ }^{a}$ & $24(27.3)$ \\
\hline
\end{tabular}

Abbreviations: AED, antiepileptic drug; PWE, person with epilepsy. a Drugs, if by any reason, were not available in hospital pharmacy, were procured from Jan Aushadhi Kendra established under PMBJP Yojana to provide quality medicine at affordable prices. 
Table 3 Results of univariate analysis comparing PWE who were adherent, partial adherent, and nonadherent to medication ( $n=88$ )

\begin{tabular}{|c|c|c|c|c|c|}
\hline Variables & Adherent & Partially adherent & Nonadherent & Total & $p$-Value \\
\hline \multicolumn{6}{|l|}{ Gender } \\
\hline Female & $10(37.0)$ & $10(45.5)$ & $17(43.60)$ & $37(42.0)$ & 0.402 \\
\hline Male & $17(63.0)$ & $12(54.0)$ & $22(56.40)$ & $51(58.0)$ & \\
\hline \multicolumn{6}{|c|}{ Age groups (in years) } \\
\hline $18-25$ & $18(66.7)$ & $05(22.7)$ & $11(28.2)$ & $34(38.6)$ & 0.063 \\
\hline $26-45$ & $08(29.6)$ & $10(45.5)$ & $15(38.5)$ & $33(37.5)$ & \\
\hline$>45$ & $01(3.7)$ & $07(31.8)$ & $13(33.3)$ & $21(23.9)$ & \\
\hline \multicolumn{6}{|l|}{ Education } \\
\hline $\begin{array}{l}\text { Illiterate or } \\
\text { primary }\end{array}$ & $03(11.1)$ & $13(59.1)$ & $31(79.5)$ & $47(53.4)$ & 0.021 \\
\hline Above primary & $24(88.9)$ & $09(40.9)$ & $08(20.5)$ & $41(46.6)$ & \\
\hline \multicolumn{6}{|l|}{ Occupation } \\
\hline Employed & $05(18.5)$ & $10(45.5)$ & $15(38.5)$ & $30(34.1)$ & 0.965 \\
\hline Unemployed & $22(81.5)$ & $12(54.5)$ & $24(61.5)$ & $58(65.9)$ & \\
\hline \multicolumn{6}{|l|}{ Marital status } \\
\hline Single & $21(77.8)$ & $07(31.8)$ & $10(25.6)$ & $38(43.2)$ & 0.212 \\
\hline Married & $06(22.2)$ & $15(68.2)$ & $29(74.4)$ & $50(56.8)$ & \\
\hline \multicolumn{6}{|l|}{ Background } \\
\hline Rural & $14(51.9)$ & $18(81.8)$ & 30 (76.9) & $62(70.5)$ & 0.699 \\
\hline Urban & $13(48.1)$ & $04(18.2)$ & $09(23.1)$ & $26(29.5)$ & \\
\hline \multicolumn{6}{|l|}{ Family composition } \\
\hline Nuclear & $15(55.6)$ & $09(40.9)$ & $20(51.3)$ & $44(50.0)$ & 0.992 \\
\hline Joint & $12(44.4)$ & $13(59.1)$ & $19(48.7)$ & $44(50.0)$ & \\
\hline \multicolumn{6}{|c|}{ Distance of residence from health care facility $(\mathrm{km})$} \\
\hline $1-10$ & $19(70.4)$ & $03(13.6)$ & $09(23.1)$ & $31(35.2)$ & 0.373 \\
\hline $11-25$ & $04(14.8)$ & $10(45.5)$ & $19(48.7)$ & $33(37.5)$ & \\
\hline$>25$ & $04(14.8)$ & $9(40.9)$ & $11(28.2)$ & $24(27.3)$ & \\
\hline \multicolumn{6}{|l|}{ Substance abuse } \\
\hline Yes & $01(3.7)$ & $05(22.7)$ & $18(46.2)$ & $24(27.3)$ & 0.003 \\
\hline No & $26(96.3)$ & $17(77.3)$ & $21(53.8)$ & $64(72.7)$ & \\
\hline \multicolumn{6}{|c|}{ Physical comorbidities } \\
\hline Yes & $02(7.4)$ & $03(13.6)$ & $16(41.0)$ & $21(23.9)$ & 0.093 \\
\hline No & $25(92.6)$ & $19(86.4)$ & $23(59.0)$ & $67(76.1)$ & \\
\hline \multicolumn{6}{|c|}{ Duration of treatment (years) } \\
\hline$<1$ & $10(37.0)$ & $02(9.10)$ & $6(15.40)$ & $18(20.50)$ & 0.070 \\
\hline $1-5$ & $08(29.6)$ & $05(22.7)$ & $10(25.6)$ & $23(26.1)$ & \\
\hline$>5$ & $09(33.3)$ & $15(68.2)$ & $23(59.0)$ & $47(53.4)$ & \\
\hline \multicolumn{6}{|l|}{ Type of therapy } \\
\hline Monotherapy & $19(70.4)$ & $06(27.3)$ & $08(20.5)$ & $33(37.5)$ & 0.003 \\
\hline Polytherapy & $08(29.6)$ & $16(72.7)$ & 31 (79.5) & $55(62.5)$ & \\
\hline \multicolumn{6}{|l|}{ Side effects by AED } \\
\hline Yes & $04(14.8)$ & $08(36.4)$ & $19(48.7)$ & $31(35.2)$ & 0.531 \\
\hline No & $23(85.2)$ & $14(63.6)$ & $20(51.3)$ & $57(64.8)$ & \\
\hline \multicolumn{6}{|l|}{ Availability of AED } \\
\hline Free & $23(85.2)$ & $17(77.3)$ & $24(61.5)$ & $64(72.7)$ & 0.906 \\
\hline Combine & $04(14.8)$ & $05(22.7)$ & $15(38.5)$ & $24(27.3)$ & \\
\hline
\end{tabular}


up to primary) (OR 0.041 [0.01-0.21]), polytherapy (OR 0.088 [0.02-0.40]), and substance use (OR 0.05 [0.01-0.58]) were found to have significant association with nonadherence to AED ( - Table 4).

Overall, forgetfulness (39.3\%) emerged out to be the most important reason for nonadherence among PWE. Feeling improved with treatment and thus not needing medicines (27.9\%) was the next most commonly cited reason for nonadherence, followed by stoppage of medication due to development of some concomitant minor ailment (21.3\%). Among extrinsic factors, unavailability of medication in hospital pharmacy $(13.1 \%)$ most commonly accounted for poor adherence. Skipping of medication due to observance of religious fasts and stopping treatment to conceal about illness from spouse and in-laws were exclusively observed among female patients (-Table 5 ).

\section{Discussion}

Previous Indian studies have suggested that low income with addition of AED expenditure were significant risk factors for nonadherence to AEDs in people with low socioeconomic

Table 4 Results of the multivariate logistic regression analysis evaluating the factors associated with partial adherence and nonadherence $(n=88)$

\begin{tabular}{|l|l|l|l|l|l|}
\hline Variables & $\begin{array}{l}\text { Adherent } \\
\text { OR }(\mathbf{9 5 \%} \mathrm{CI})\end{array}$ & $\begin{array}{l}\text { Partial adherent } \\
\text { OR }(\mathbf{9 5 \%} \mathrm{CI})\end{array}$ & $\boldsymbol{p}$-Value & $\begin{array}{l}\text { Nonadherent } \\
\text { OR }(\mathbf{9 5 \%} \mathrm{Cl})\end{array}$ & $\boldsymbol{p}$-Value \\
\hline Illiterate or primary education & 1 & $0.100(0.02-0.48)$ & $\mathbf{0 . 0 0 4}$ & $0.041(0.01-0.21)$ & $<\mathbf{0 . 0 0 1}$ \\
\hline Polytherapy & 1 & $0.143(0.03-0.60)$ & $\mathbf{0 . 0 0 8}$ & $0.088(0.02-0.40)$ & $\mathbf{0 . 0 0 2}$ \\
\hline Substance abuse & 1 & $0.136(0.01-1.65)$ & 0.117 & $0.05(0.01-0.58)$ & $\mathbf{0 . 0 1 7}$ \\
\hline
\end{tabular}

Note: Values in bold indicate significance at $p \leq 0.05$.

Table 5 Reasons of nonadherence to AED $(n=61)$

\begin{tabular}{|c|c|c|}
\hline Reasons & $N(\%)$ & $\mathrm{M}: \mathrm{F}$ \\
\hline \multicolumn{3}{|l|}{ Intrinsic } \\
\hline Patient thought that medication was not necessary for the condition & $02(3.3)$ & $1: 1$ \\
\hline Patient thought that medication was ineffective in treating the condition & $04(6.6)$ & $4: 0$ \\
\hline $\begin{array}{l}\text { Patient had not clearly understood how to take prescription (frequency, timing, strength of AED), so was } \\
\text { not taking prescribed dose) }\end{array}$ & $02(3.3)$ & $2: 0$ \\
\hline $\begin{array}{l}\text { Patient thought that dose of AED prescribed to him was too high, so took less than prescribed dose by } \\
\text { himself }\end{array}$ & $08(13.1)$ & $0.6: 1$ \\
\hline Patient took the medicine and it gave him / her problems (side effects) & $04(6.6)$ & $1: 1$ \\
\hline Patient felt bored of taking medicine for so long & $12(20.0)$ & $0.42: 1$ \\
\hline Patient felt better/improved so did not need the medicine & $17(27.9)$ & $1.13: 1$ \\
\hline Patient forgot to take the medication & $24(39.3)$ & 1.78:1 \\
\hline Patient had to travel away from home and did not take medication along with & $06(2.5)$ & $2: 1$ \\
\hline Patient switched to alternate form of treatment (like ayurvedic, homeopathic) & $07(11.5)$ & 1.33:1 \\
\hline $\begin{array}{l}\text { Patient stopped taking AED due to development of some other minor medical ailment (fever, flu, diar- } \\
\text { rhea, etc.) }\end{array}$ & $13(21.3)$ & $3.3: 1$ \\
\hline $\begin{array}{l}\text { Patient had no idea of how long to continue treatment so stopped taking medication by himself after } \\
\text { some time. }\end{array}$ & $07(11.5)$ & $6: 1$ \\
\hline $\begin{array}{l}\text { Patient wanted to hide about illness and treatment from spouse and in-laws after marriage due to anticipa- } \\
\text { tion of adverse marital outcome or stigma }\end{array}$ & $06(2.5)$ & $0: 6$ \\
\hline Patient stopped taking AED as he/she was observing religious fasting & $04(6.6)$ & $0: 4$ \\
\hline \multicolumn{3}{|l|}{ Extrinsic } \\
\hline Patient thought that medication cost too much & $05(8.2)$ & $4: 1$ \\
\hline $\begin{array}{l}\text { Patient could not get to the pharmacy due to long queue/waiting period/reaching after pharmacy had } \\
\text { closed. }\end{array}$ & $01(1.6)$ & $1: 0$ \\
\hline The prescribed medicine had run out of stock & $08(13.1)$ & $1.67: 1$ \\
\hline $\begin{array}{l}\text { Patient felt that the health care provider had not adequately told him about drug regimen and dosing } \\
\text { schedule }\end{array}$ & $06(2.5)$ & $2: 1$ \\
\hline Patient felt that medications were too many in number (polypharmacy) & $05(8.2)$ & $4: 1$ \\
\hline Patient felt that the drug regimen is too complex to follow & $06(2.5)$ & $2: 1$ \\
\hline Patient could not come to get prescription renewed due to personal reasons (any adverse life events, etc.) & $01(1.6)$ & $1: 0$ \\
\hline
\end{tabular}

Abbreviation: PWE, person with epilepsy. 
status. ${ }^{5,6,8}$ Our study is an effort toward understanding factors behind poor adherence among BPL PWE. Assessment of factors in economically weaker sections of the society can be used to develop measures toward addressing these factors and can help in improving treatment outcomes in poor people with epilepsy. In the present study, only $30.7 \%$ of patients were found to be adherent, whereas $25 \%$ and $44.3 \%$ of the patients were partial and nonadherent, respectively, when assessed using MARS. Low education (illiterate or primary), polytherapy, and substance use were observed to have significant association with nonadherence.

Previous Indian studies using very similar tests have shown the fairly comparable results regarding prevalence of poor adherence in PWE. A previous study by Verma et al found that $57 \%$ of persons with epilepsy had moderate-to-low level of treatment adherence, as evaluated using the MoriskyGreen test. ${ }^{8} \mathrm{~K}$ Das evaluated 1450 patients of epilepsy and found that $42.75 \%$ of the patients discontinued epilepsy treatment, which is similar to the present study. ${ }^{5}$ However, much lower rate of nonadherence $(27.7 \%$ ) was seen in study by Gurumurthy et al using the four-item Morisky medication adherence scale. It might be because of different parameters used for measuring nonadherence or inclusion of population from all socioeconomic strata. ${ }^{6}$

In the index study, it was found that in patients who were on polytherapy, nonadherence was significantly more when compared with those on monotherapy. These findings synchronize with the previous international studies, where a similar observation was made that when multiple AEDs are prescribed, adherence level goes down significantly. This is quite understandable that patients are likely to falter more if the treatment regimen is complex, where loads of pills need to be taken at frequent intervals. ${ }^{9-12}$ However, this observation is in conflict with the previous Indian studies by Das et al and Gurumurthy et al, where they failed to notice any such association. ${ }^{5,6}$ Simplifying dosage schedule, usage of pill dispensers, supervision, and timely reminders from family members or caregivers about medications can help in improving adherence in patients on polytherapy.

Substance abuse was found to be another significant factor influencing adherence rates in our study. This can be explained by the fact that alcohol or drug abuse in a person makes it difficult to prioritize adherence. Most of the studies conducted on the PWE did not take into account influence of substance abuse on AED adherence. Involving families, social support, and special psychosocial interventions targeting substance abuse behavior can help in improving adherence in people with substance abuse.

A significant association between AED nonadherence and lower educational attainment was found in the index study. Patients with low education may not always be able to follow the prescription and instructions as told. This finding matches with the observations of study by Gurumurthy et al who also found that people with epilepsy belonging to lower socioeconomic class (classified according to Kuppuswamy's socioeconomic status scale, which takes into account education as well) have significantly higher nonadherence. Lower education might lead to poor understanding of the illness and treatment regimen, rigid indigenous beliefs, and attitudes leading to poor treatment adherence, which can be addressed by educational intervention and lead to improved adherence. ${ }^{13}$

In our study, we failed to find any significant association of age and gender with AED adherence. Previous studies have also shown inconclusive results with regard to association between age and adherence. This finding is in line with the previous studies from India and across the globe, ${ }^{6,8,9,14}$ which did not find any significant differences among various age groups for AED adherence. This observation, however, differs from that of Ferrari et $\mathrm{al}^{15}$ who found younger patients from Brazil to be less adherent to AEDs. In contrast, Lusic et al in Croatia observed that elderly patients were more likely to be nonadherent ${ }^{11,12}$ In the present study, gender was not found to have any significant effect on the adherence rate concurrent to the findings by Gurumurthy et al, Liu et al, and Johnbull et al. , $, 10,13$

Likewise, other demographic factors like marital status, family composition, occupation, rural-urban background, and distance of residence from health care facility were not found to have any significant influence on adherence rates. Gurumurthy et al also did not find marital status to be affecting adherence. ${ }^{6}$ However, marital disharmony was found to be a significant factor behind discontinuation of AED therapy in a study by Das et al. ${ }^{5}$

A total of 31 (35.2\%) patients experienced side effects of AED therapy. Most of these side effects were benign and were not found to have any significant influence on AED adherence, similar to the findings by Gurumurthy et al. ${ }^{6}$ Similarly, duration of treatment was not found to be have statistically significant impact on adherence rates. This finding is corroborated by studies from Gurumurthy et al and Gabr et $\mathrm{al},{ }^{6,9}$ which failed to find any association of the duration of epilepsy with medication adherence. In contrast, a significant and direct relationship was found between duration of illness and nonadherence in PWE by Verma et al. ${ }^{8}$

On evaluation of the reasons behind nonadherence, the most common reason for poor adherence was cited to be forgetfulness, which is supported by the findings of studies by Gurumurthy et al and Liu et al.,14 Johnbull et al has also reported forgetfulness to be the most common reason behind nonadherence in their study cohort, which has striking resemblance with our study in terms of proportion of patients (around 40\%) citing this reason for poor adherence. ${ }^{16,17}$ The most common, among extrinsic reasons of nonadherence, was unavailability of medication in hospital pharmacy, as these patients were unable to afford purchasing of medicines, even if it was available at much cheaper rates at Jan Aushadhi Kendra established in hospital premises, thus emphasizing the need for continuous financial support from government for treatment of poor PWE. Das et al also observed that majority (90\%) of the patients discontinued AED therapy due to cost factors and 20\% due to local nonavailability of medicines. Stopping antiepileptic treatment to conceal details about illness from spouse or in-laws due to anticipated adverse marital outcome or stigmatization was exclusively observed among females. Problems faced by married women with epilepsy also been reported in a 
previous Indian study by Sharma et al on. ${ }^{18}$ Skipping doses due to observance of religious fasts was another reason cited exclusively by female patients with epilepsy.

\section{Conclusion}

In the present study, only $30.7 \%$ of patients were found to be adherent and $44.3 \%$ of the patients had poor adherence. Low education, polytherapy, and substance abuse were found to have significant association with poor adherence among BPL patients with epilepsy. This study emphasizes the need for upliftment of economic status and improved educational level in general, and in developing countries like India where many still live below the poverty line. Educational interventions by heath care workers can have a positive influence on medication adherence in PWE from low economic and educational background. Substance abuse should also be addressed during treatment counselling. Monotherapy should be considered wherever possible in the management of epilepsy, which avoids unnecessary costs and adverse effects. Parents of girls with epilepsy should be encouraged to make an honest disclosure of their illness status prior to marriage to reduce poor medication adherence postmarriage to save the marriage. The study has used standard scale of adherence and standard definition of poverty, although the possibility of recall bias leading to overestimation of adherence cannot be denied.

\section{Authors' Contributions}

N. G. and S. C. contributed in the concept, study design, data collection, literature search, manuscript preparation and editing, and manuscript review. N. G. contributed in the concept, study design, statistical analysis, literature search, manuscript preparation and editing, and manuscript review. A. S. K. contributed in the concept, study design, literature search, and manuscript preparation and editing. A. N. and P. S. contributed in literature search, manuscript preparation and editing, and manuscript review.

\section{Funding}

None.

\section{Conflict of Interest}

None declared.

\section{References}

1 Hauser WA, Kurland LT. The epidemiology of epilepsy in Rochester, Minnesota, 1935 through 1967. Epilepsia 1975; 16(1):1-66
2 Epilepsy. Fact Sheet No. 999. World Health Organization. Available at: http:/ www.who.int/mediacentre/factsheets/fs999/ en/. Accessed May 12, 2020.

3 Kwan P, Brodie MJ. Early identification of refractory epilepsy. N Engl J Med 2000;342(5):314-319

4 Kaddumukasa M, Kaddumukasa M, Matovu S, Katabira E. The frequency and precipitating factors for breakthrough seizures among patients with epilepsy in Uganda. BMC Neurol 2013; $13: 182$

5 Das K, Banerjee M, Mondal GP, Devi LG, Singh OP, Mukherjee BB. Evaluation of socio-economic factors causing discontinuation of epilepsy treatment resulting in seizure recurrence: a study in an urban epilepsy clinic in India. Seizure 2007; 16(7):601-607

6 Gurumurthy R, Chanda K, Sarma G. An evaluation of factors affecting adherence to antiepileptic drugs in patients with epilepsy: a cross-sectional study. Singapore Med J 2017;58(2): 98-102

7 Jimmy B, Jose J. Patient medication adherence: measures in daily practice. Oman Med J 2011;26(3):155-159

8 Verma A, Kiran K, Kumar A. Belief in medication and adherence to antiepileptic drugs in people with epilepsy: a cross-sectiona study from rural India. Int J Neurosci 2018;128(12):1168-1173

9 Gabr WM, Shams ME. Adherence to medication among outpatient adolescents with epilepsy. Saudi Pharm J 2015; 23(1):33-40

10 Bautista RE, Rundle-Gonzalez V. Effects of antiepileptic drug characteristics on medication adherence. Epilepsy Behav 2012;23(4):437-441

11 Harimanana A, Clavel S, Chivorakul P, Perez F, Preux PM, Barennes $\mathrm{H}$. Associated factors with adherence to antiepileptic drug in the capital city of Lao PDR. Epilepsy Res 2013; 104(1-2):158-166

12 Jones RM, Butler JA, Thomas VA, Peveler RC, Prevett M. Adherence to treatment in patients with epilepsy: associations with seizure control and illness beliefs. Seizure 2006 ;15(7):504-508

13 Ibinda F, Mbuba CK, Kariuki SM, et al. Evaluation of Kilifi epilepsy education programme: a randomized controlled trial. Epilepsia 2014;55(2):344-352

14 Liu J, Liu Z, Ding H, Yang X. Adherence to treatment and influencing factors in a sample of Chinese epilepsy patients. Epileptic Disord 2013;15(3):289-294

15 Ferrari CM, de Sousa RM, Castro LH. Factors associated with treatment non-adherence in patients with epilepsy in Brazil. Seizure 2013;22(5):384-389

16 Lusić I, Titlić M, Eterović D. Suradljitvost bolesnika s epilepsijom [Epileptic patient compliance with prescribed medical treatment]. Acta Med Croatica 2005; 59(1):13-18

17 Johnbull OS, Farounbi B, Adeleye AO, Ogunrin O, Uche AP. Evaluation of factors influencing medication adherence in patients with epilepsy in rural communities of Kaduna State, Nigeria. Neurosci Med 2011;2:299-305

18 Sharma SK, Sardana V, Maheshwari D, et al. Problems faced by married women with epilepsy in Indian Scenario: A hospital-based study. Int J Epilepsy 2018;5:80-86 